\title{
Immediate Effects of Intravenous Verapamil in Cardiac Arrhythmias
}

\author{
L. SCHAMROTH, D. M. KRIKLER, C. GARRETT
}

British Medical fournal, 1972, 1, 660-662

\section{Summary}

Verapamil was administered by intravenous injection to 181 patients with various cardiac arrhythmias. The automaticity of the cardiac pacemaker was slowed in sinus, idionodal, and idioventricular tachycardia. In atrial fibrillation the drug usually slowed the ventricular response and often made it regular. In some cases atrial flutter was converted to sinus rhythm, the ventricular response being reduced in the remainder. Conversion of paroxysmal supraventricular tachycardia to sinus rhythm was consistently achieved. A favourable response occurred in four patients in whom arrhythmias were associated with pre-excitation syndromes. There were no adverse clinical side effects.

\section{Introduction}

Verapamil (Cordilox, Isoptin), originally introduced for the treatment of myocardial ischaemia (Hoffman, 1964; Sandler et al., 1968; Sowton, 1969), has been shown to have antiarrhythmic properties (Melville et al., 1964; Bender et al., 1966; Rodrigues-Pereira and Viana, 1968). It has been found to reduce the ventricular rate and also to regularize the ventricular response in atrial fibrillation (Schamroth, 1971). We have studied its action in other arrhythmias as well as in a larger series of cases of atrial fibrillation.

\section{Patients and Methods}

We tested verapamil in 181 patients ( 100 women and 81 men) aged 9 to 88 years. The ages of the patients with atrial fibrillation in the Johannesburg series ranged from 9 to 88 years (mean 38, median 42) and from 46 to 84 years (mean and median 62) in the London series. All the Johannesburg patients were African (Negro), while all but one (a Jamaican) in London were Caucasian. Moderate to severe cardiac disability was present in 132 cases. Altogether 143 patients were on digitalis at the time of the trial, including 103 of the 115 with atrial fibrillation. The nature of the underlying disease is shown in Table $I$ and the various arrhythmias are listed in Table II.

TABLE I-Nature of Underlying Disease in the 181 Patients

\begin{tabular}{|c|c|c|c|c|c|c|c|}
\hline \multirow{2}{*}{\multicolumn{2}{|c|}{ Chronic rheumatic heart disease }} & & & & & & No. of Case \\
\hline & & & .. & .. & . & .. & .. 77 \\
\hline Hypertensive heart disease & & .. & .. & . & . & .. & 33 \\
\hline haemic heart disease & & .. & .. & .. & .. & .. & . \\
\hline iomyopathy & $\therefore$ & $\ldots$ & .. & .. & .. & .. & .. \\
\hline yrotoxicosis & . & .. & .. & .. & .. & . & . \\
\hline nstrictive pericarditis & .. & .. & .. & .. & . & . & $\therefore$ \\
\hline rronic cor pulmonale & $\therefore$ & .. & .. & .. & .. & . & .. \\
\hline Pre-excitation syndrome & .. & .. & . & .. & .. & . & .. \\
\hline No overt heart disease & $\because$ & $\because$. & .. & .. & .. & . & 15 \\
\hline
\end{tabular}

Baragwanath Hospital and University of the Witwatersrand, Johannesburg, South Africa

LEO SCHAMROTH, M.D., F.R.C.P., Consultant Physician

Cardiac Department, Prince of Wales's Hospital, London N15 4AW DENNIS M. KRIKLER, F.R.C.P., F.A.C.C., Consultant Physician CHRISTINE GARRETT, M.B., B.S., D.C.H., Senior House Officer
TABLE II-Response to Verapamil in the 181 Patients with Arrhythmias

\begin{tabular}{|c|c|c|}
\hline Arrhythmia & $\begin{array}{l}\text { No. } \\
\text { Cases }\end{array}$ & Response \\
\hline $\begin{array}{l}\text { Sinus tachycardia } \\
\text { Idionodal tachycardia } \\
\text { Idioventricular tachycardia }\end{array}$ & $\left.\begin{array}{l}3 \\
3 \\
1\end{array}\right\}$ & $\begin{array}{l}\text { Significant slowing in all } \\
\text { Conversion to sinus rhythm in all } \\
\text { Ventricular slowing in } 111\end{array}$ \\
\hline Atrial fibrillation $\quad$. & 115 & Ventricular regularization in 71 \\
\hline Atrial flutter & 15 & $\left\{\begin{array}{l}\text { Conversion to sinus rhythm in } 4 \\
\text { Decreased ventricular response in } 11\end{array}\right.$ \\
\hline $\begin{array}{l}\text { Paroxysmal supraventricular } \\
\text { tachycardia } \\
\text { Paroxysmal ventricular } \\
\text { tachycardia }\end{array}$ & $\begin{array}{r}20 \\
1\end{array}$ & $\begin{array}{l}\text { Conversion to sinus rhythm in all } \\
\text { No effect }\end{array}$ \\
\hline Ventricular extrasystoles & 23 & $\left\{\begin{array}{l}\text { Reduced or abolished in } 11 \\
\text { No effect in } 12\end{array}\right.$ \\
\hline
\end{tabular}

Before having the injection each patient rested in bed for 20 minutes, the blood pressure was measured, and a 90-second control E.C.G. tracing was recorded. Verapamil $(10 \mathrm{mg})$ was then injected intravenously over $15-30$ seconds. In patients with atrial fibrillation and in some with other arrhythmias further 90-second E.C.G. recordings were made one and five minutes after the injection; in the remainder continuous tracings were taken for up to six minutes. Subjects were carefully questioned for subjective effects and the blood pressure was recorded again five minutes after the injection. In atrial fibrillation the rates were compared in the control and test tracings (Schamroth, 1971).

\section{Results}

The effects in various arrhythmias are shown in Table II. There was a significant slowing (average $27 \%$ ) of the sinus rate in the three patients with sinus tachycardia. Change to sinus

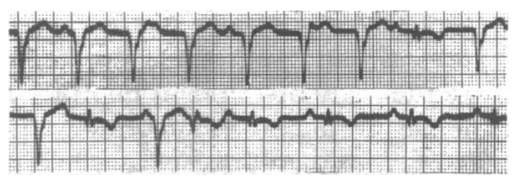

FIG. 1-E.C.G. (continuous strip of lead II) showing idioventricular tachycardia (top strip). Return cycle after first capture beat (top strip) is shorter $(0.64 \mathrm{sec})$ than return cycle of second capture beat (bottom strip) $(0.76 \mathrm{sec})$. Subsequent conversion to sinus rhythm occurred 36 seconds after completion of injection.

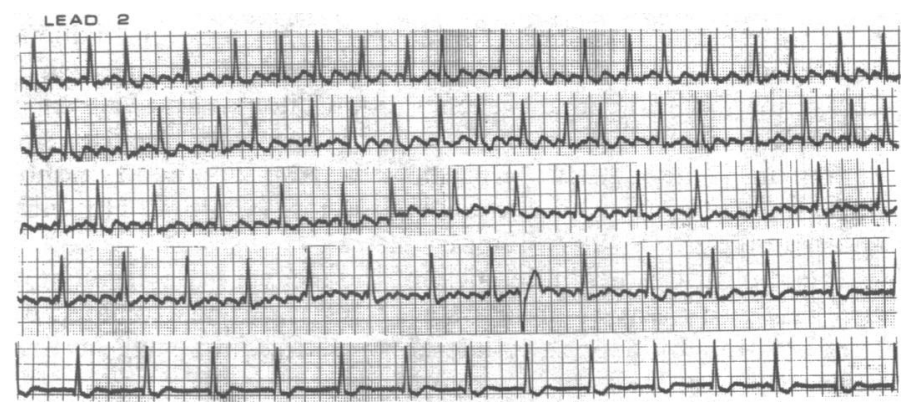

FIG. 2-Continuous E.C.G. showing atrial fibrillation with irregular ventricular response (top 2 strips); slowing and regularization of ventricular response (3rd to 5th strips); and decrease in amplitude of fibrillatory waves (bottom strip). 
rhythm occurred in all three cases of idionodal tachycardia and in the single patient with idioventricular tachycardia (Fig. 1). The longer return cycle of the second capture beat illustrated in Fig. 1 shows selective slowing of the enhanced idioventricular rhythm.

The effects in atrial fibrillation are well seen in Fig. 2. Diminution of the ventricular response occurred in 111 cases, with slowing of up to $60 \%$ compared with the control tracings; this

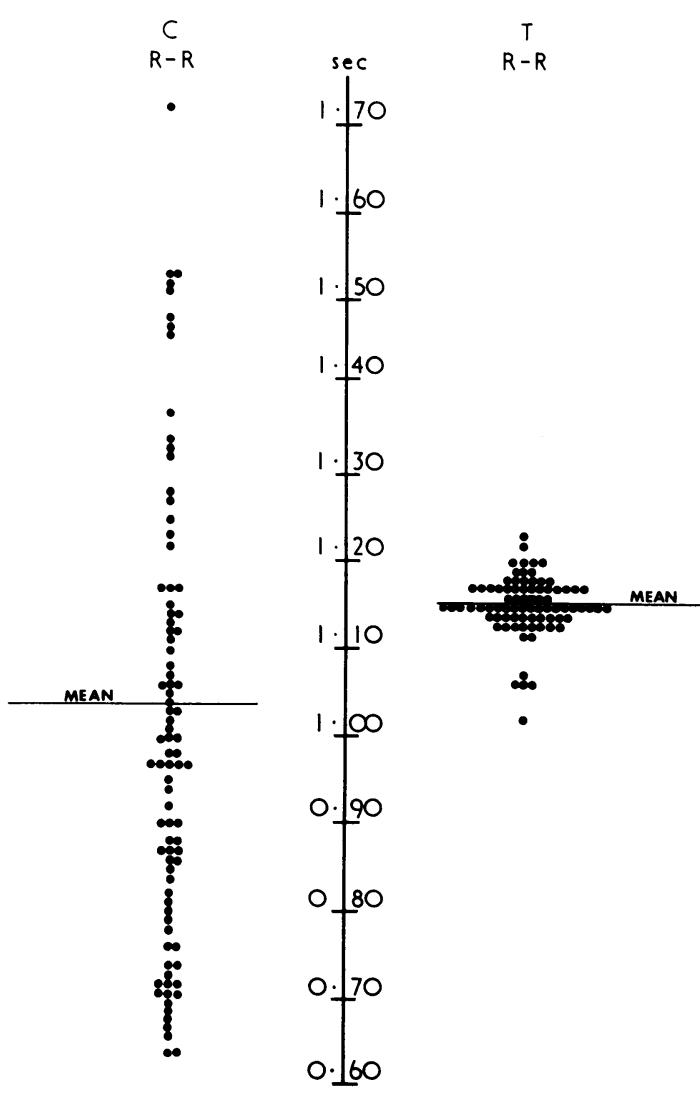

FIG. 3-Distribution of R-R intervals in tracings before (C) and after (T) verapamil in patient with atrial fibrillation. (Reproduced by courtesy of the editor of Cardiovascular Research).

was usually most noticeable when the control rate was fast. In addition ventricular response became more regular in $71 \%$ of the Johannesburg series and in $30 \%$ of the London series. This is illustrated by the change in the scatter of the R-R intervals in one patient (Fig. 3). There was distinct diminution in the amplitude of the fibrillatory waves in $44 \%$ of the subjects. Conversion to sinus rhythm occurred once.

Four of the 15 cases of atrial flutter were converted to sinus rhythm; this was sometimes preceded by an increase in the atrioventricular (A-V) block and by transient atrial fibrillation (Fig. 4). In the remaining 11 cases the ventricular response

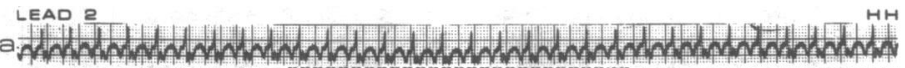

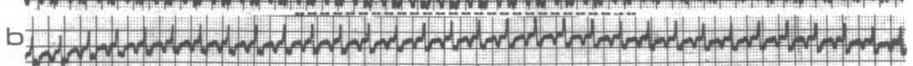

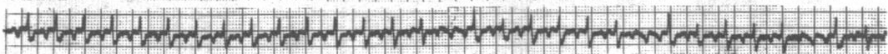

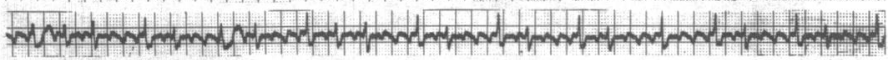

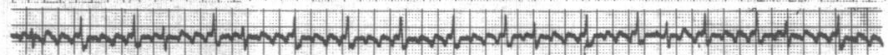

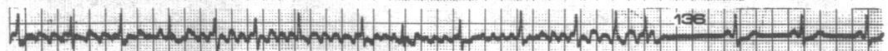

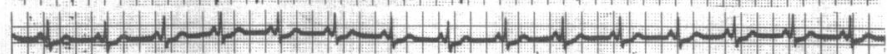

FIG. 4-a, Control tracings: atrial flutter with 2:1 A-V block. b, Continuous recording showing increase in degree of $\mathrm{A}-\mathrm{V}$ block (3rd and 4th strips) transient atrial fibrillation (5th strip); and conversion to normal sinus rhythm (bottom strip). Note short P-R interval (Lown-Ganong-Levine syndrome). decreased (Fig. 5). All 20 cases of paroxysmal supraventricular tachycardia were converted to sinus rhythm, usually within two minutes (Figs. 6 and 7). There was no effect in the single case of paroxysmal ventricular tachycardia. This patient also failed to respond to intravenous lignocaine and required direct-current conversion. Ventricular extrasystoles were reduced or abolished in half of the cases but there was no effect in the remainder.
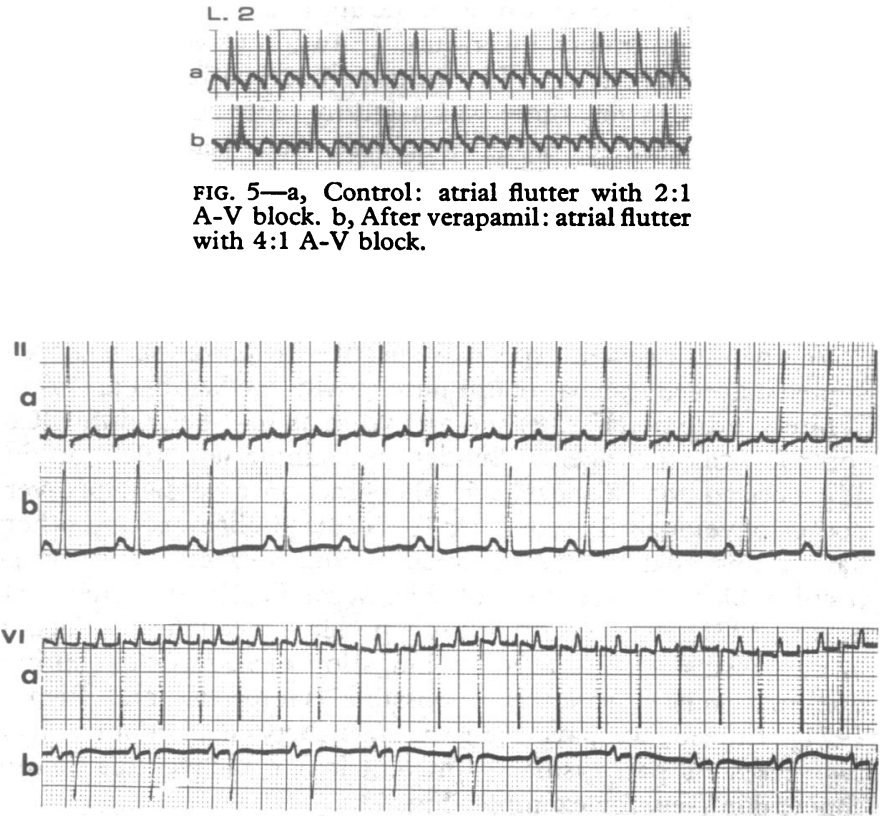

FIG. 6-a, Control: extrasystolic atrial tachycardia. b, Sinus rhythm after verapamil.

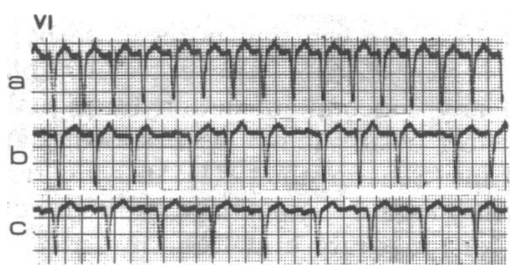
FIG. 7 -a, Control: extrasystolic atrial tachycardia ( 167 beats/min) with $1: 1$
A-V conduction. b, Four minutes after verapamil: extrasystolic atrial tachycardia ( 113 beats/min) with $4: 3$ second-degree A-V block (Wenckebach cardia ( 113 beats/min) with $4: 3$ second-degree A-V
type). c, Sinus rhythm. Six minutes after verapamil.

A pre-excitation syndrome was present in four of the above cases. Two had the Lown-Ganong-Levine syndrome of short $P-R$ interval and normal QRS complexes. One with atrial fibrillation showed ventricular slowing after verapamil, and the other, with atrial flutter, converted to sinus rhythm (Fig. 4). The other two had type A Wolff-Parkinson-White syndrome with paroxysmal supraventricular tachycardia and responded promptly to verapamil (Fig. 8).

There were no adverse side effects, and no appreciable fall in blood pressure or precipitation or aggravation of cardiac failure occurred.

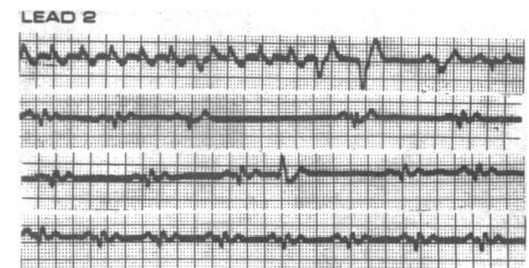

FIG. 8-Continuous tracings: paroxysmal supraventricular tachycardia with conversion to sinus rhythm (Wolff-Parkinson-White syndrome) two minutes after verapamil. 


\section{Discussion}

Verapamil acts promptly by intravenous injection in many cardiac arrhythmias. Maximum blood levels are reached 3 to 12 minutes after injection, the concentration then falling rapidly to zero within 20 to 30 minutes (Melville et al., 1969). Its antiarrhythmic action during general anaesthesia lasts about 30 minutes (Brichard and Zimmerman, 1970). We have found such single doses safe; none of the patients suffered any ill effects. Rydén and Saetre (1971) observed no appreciable haemodynamic effects after continuous intravenous infusion of verapamil in 10 patients in sinus rhythm. In two digitalized patients with atrial fibrillation, however, there was a fall in ventricular rate, blood pressure, and cardiac output though the stroke volume increased. Verapamil has been shown not to block the effects of isoprenaline on ventricular stroke volume (Ross and Jorgensen, 1967). Its failure to block the action of isoprenaline on the bronchioles (Hills, 1970) suggests that it will be especially useful where some beta-adrenergic blockers might be hazardous.

Verapamil proved especially useful in paroxysmal supraventricular tachycardia. In one patient with the Wolff-ParkinsonWhite syndrome (Fig. 8) the arrhythmias had been difficult to control with other agents. Bender and Zimmerhof (1967) originally noticed the Wenckebach phenomenon as a sign of overdosage of verapamil when given for cardiac ischaemia, and others have found that it may produce varying degrees of atrioventricular block (Brichard and Zimmerman, 1970; Rydén and Saetre, 1971). This may point to a possible mechanism of action in paroxysmal tachycardia. Prolongation of intranodal conduction may render re-entry impossible (Goldreyer and Bigger, 1971). Indeed, we have seen the Wenckebach phenomenon in two cases of paroxysmal supraventricular tachycardia before conversion (see, for example, Fig. 7).

Primary slowing action on pacemaker automaticity is evident from the response in sinus tachycardia and from the abolition of idionodal and idioventricular tachycardia, where verapamil allows the sinus pacemaker to regain control. In atrial flutter and fibrillation it slows the ventricular response by increasing the physiological second-degree atrioventricular block over and above that of any concomitant action by digitalis. Where the regularizing effect occurs it has been shown statistically to be highly significant (Schamroth, 1971); it is less frequent in older patients, which probably explains the differences in response between the Johannesburg and London series. Regularization of the ventricular response in atrial fibrillation is, of course, desirable as it may improve ventricular function (Gibson et al., 1971). Intravenous verapamil, however, can be of only shortterm benefit here, and our limited experience with oral therapy has so far been unpromising. It has been postulated that tissue concentrations after ingestion by mouth may be inadequate for the acute treatment of arrhythmias (Bender, 1967).

The mechanism of this regularizing effect is uncertain. Conversion to atrioventricular nodal (idionodal) rhythm seems unlikely since there are still minor fluctuations in the ventricular rhythm (Fig. 3). It may result from a stabilizing effect on the varying degrees of concealed atrioventricular nodal conduction, which may cause the irregular ventricular response in atrial fibrillation-perhaps by increasing the absolute, but not relative, refractory period. An activation front approaching the atrioventricular node from the direction of the sinoatrial node is well transmitted, whereas a front approaching from other directions may be delayed or blocked (Janse, 1969). Verapamil may stabilize the chaotic atrial activation front.

Verapamil does not act therapeutically as a beta-adrenergic blocker (Ross and Jorgensen, 1967; Brichard and Zimmerman, 1970), nor does it have a quinidine-like action (Singh and Vaughan-Williams, 1972); as a calcium-ion antagonist and thus an antagonist of electromechanical coupling (Fleckenstein et al., 1968) it may belong to a novel class of antiarrhythmic agents (Singh and Vaughan-Williams, 1972).

Our experience with verapamil for the immediate control of a variety of cardiac arrhythmias has been promising. We have not tried it by continuous intravenous infusion because those patients who responded did so promptly to single injections. It would seem prudent to use verapamil cautiously in the presence of atrioventricular block. However, apart from atrial flutter, where we sometimes found it useful and never hazardous, we do not feel that it will need to be used under these circumstances. The effects in atrial fibrillation are of great theoretical interest and under certain circumstances may be of therapeutic value.

Requests for reprints should be addressed to D.M.K., Prince of Wales's Hospital, London N15 4AW.

\section{References}

Bender, F. (1967). Medizinische Klinik, 62, 634.

Bender, F., Kojima, N., Reploh, M. D., and Oelmann, G. (1966). Medizinische Welt, 17, 1120 .

Bender, F., and Zimmerhof, K. (1967). Medizinische Welt, 18, 1585.

Brichard, G., and Zimmerman, P. E. (1970). British fournal of Anaethesia, 42, 1005.

Fleckenstein, A., Doring, H. J., and Kammermeier, H. (1968). Klinische Wochenschrift, 46, 343.

Gibson, D. G., Broder, G., and Sowton, E. (1971). British Heart fournal, 33, 388.

Goldreyer, B. N., and Bigger, J. T., jun. (1971). Circulation, 43, 15.

Hills, E. A. (1970). British fournal of Clinical Practice, 24, 116

Hoffmann, P. (1964). Medizinische Klinik, 59, 1387.

Hoffmann, P. (1964). Medizinische Klinik, 59, 1387.

Janse, M. J. (1969). Circulation Research, 25, 439. Aville, K. L., Shister, H. E.,

Melville, K. L., Shister, H. E., Mignault, J. de L., and Garvey, L. (1969). Union Médicale du Canada, 98, 1.

Rodrigues-Pereira, E., and Viana, A. P. (1968). Arzneimittel-Forschung, 18, 175 .

Ross, G., and Jorgensen, C. R. (1967). Fournal of Pharmacology and Experimental Therapeutics, 158, 504.

Rydén, L., and Saetre, H. (1971). European fournal of Clinical Pharmacology, $3,153$.

Sandler, G., Clayton, G. A., and Thornicroft, S. G. (1968). British Medical Fournal, 3, 224.

Schamroth, L. (1971). Cardiovascular Research, 5, 419.

Singh, B. N., and Vaughan-Williams, E. M. (1972). Cardiovascular Research.

In press. 